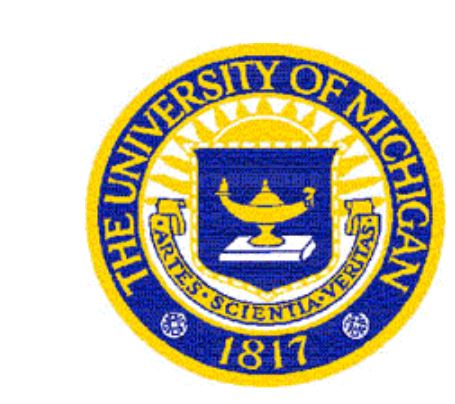

\title{
Ruthenium Aluminides: Deformation Mechanisms and Substructure Development
}

\author{
Final Report \\ Submitted to the \\ Department of Energy \\ Grant Number DE-FG02-00ER45820
}

By

Tresa M. Pollock

Department of Materials Science and Engineering

University of Michigan

Ann Arbor, MI 48109

May 11, 2005 


\section{Ruthenium Aluminides: Deformation Mechanisms and Substructure Development}

Table of Contents

Page

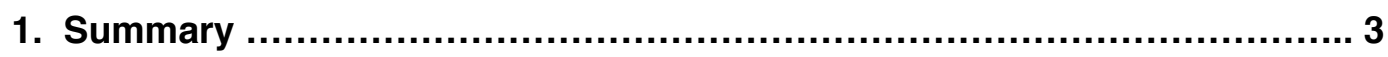

2. Slip Systems in RuAl - Low Temperatures............................ 3

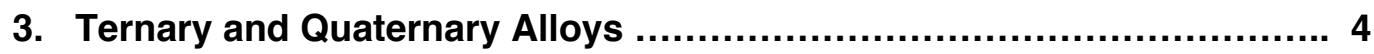

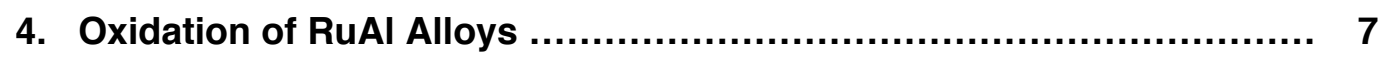

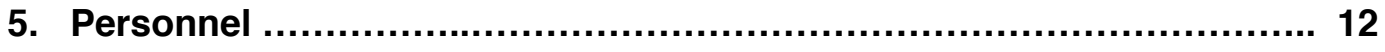

6. Publications and Presentations.............................................. 12

7. References.............................................................. 13 


\section{Summary}

Structural and functional materials that can operate in severe, high temperature environments are key to the operation of a wide range of energy generation systems. Because continued improvements in the energy efficiency of these systems is critical, the need for new materials with higher temperature capabilities is inevitable. Intermetallic compounds, with strong bonding and generally high melting points offer this possibility for a broad array of components such as coatings, electrode materials, actuators and/or structural elements. For most applications some degree of intrinsic deformability is desirable for durability under thermal cycling conditions.

RuAl is a very unusual intermetallic compound among the large number of B2 compounds that have been identified and investigated to date. This material has a very high melting temperature of $2050^{\circ} \mathrm{C}$, low thermal expansion, high thermal conductivity and good corrosion resistance. Unlike most other high temperature B2 intermetallics, RuAl possesses good intrinsic deformability at low temperatures [1 - 8 ]. In this program, fundamental aspects of low and high temperature mechanical properties and deformation mechanisms in binary and higher order RuAl-based systems have been investigated. Alloying additions of interest included platinum, boron and niobium. Additionally, preliminary studies on high temperature oxidation behavior of these materials have been conducted.

In comparison to other B2 compounds, a number of unusual features of the behavior of this class of intermetallics have been discovered. TEM studies of stoichiometric RuAl indicate that deformation occurs by glide of both $<100>$ and $<011>$ dislocations within individual grains, giving five independent slip systems. These slip systems operate over a wide range of temperature, from $-196^{\circ} \mathrm{C}$ to $1050^{\circ} \mathrm{C}$. Additionally, the addition of 2 at $\%$ Pt results in a transition to $<111>$ slip. No other high melting point $\mathrm{B} 2$ intermetallic is known to deform by any of these slip modes. Additionally, preliminary high temperature creep experiments demonstrate an exceptionally high creep strength for RuAl at $1050^{\circ} \mathrm{C}$. For a fixed creep rate RuAl can sustain stresses that are approximately a factor of $25 \mathrm{X}$ higher, compared to NiAl. The oxidation properties are also very unusual, with the formation of alternating layers of $\mathrm{Al}_{2} \mathrm{O}_{3}$ and $\square-\mathrm{Ru}$ as a result of exposures in the temperature range of $1000^{\circ} \mathrm{C}-1200^{\circ} \mathrm{C}$. Pt additions provided substantial improvements in oxidation rates. A more in-depth description of the research is provided in the following sections. Additional details are given in manuscripts published as a result of this research program, listed in Section 6.

\section{Slip Systems in RuAl - Low Temperatures}

All experiments have been performed on polycrystalline RuAl alloys prepared by arcmelting or levitation melting, following by annealing at either $1300^{\circ} \mathrm{C}$ or $1500^{\circ} \mathrm{C}$. To first understand the unusual low temperature deformation behavior of this class of materials, detailed transmission electron microscopy studies were conducted on polycrystalline RuAl deformed at room temperature and 77K. Fig. 2(a) shows a low magnification view 
of the dislocation substructure following $2 \%$ deformation at room temperature. The Burgers vectors of a large fraction of the dislocations are indicated on the figure. It is apparent that the substructure is composed of a mixture of $<110>$ and $<100>$ type dislocations on $\{110\}$ type planes. Both types of dislocations could be generally characterized as curved and lacking any obvious preferred orientations or alignment with surrounding dislocations. Short segments of $<111>$ dislocations were occasionally observed but did not appear to be mobile. Dislocation substructures in RuAl deformed to higher strains $(\sim 7 \%)$ at room temperature contained a much higher dislocation density, with dislocations tangles and cell-like clustering. Additional analyses of RuAl following deformation at $77 \mathrm{~K}$ revealed a substructure very similar to that observed at room temperature, Fig. 2(b), with a mixture of curved $<110\rangle$ and $<001>$ type dislocations. Again, similar densities of each of the two types of dislocations were observed within individual grains. This is significant since the combination of $<110>\{110\}$ and $<100>\{011\}$ systems can provide five independent slip systems required for plastic compatibility in polycrystalline material. Additionally, strain rate change experiments were conducted to measure rate sensitivity. Rate sensitivities in binary RuAl (as well as a large number of ternary RuAl-based compositions) were very low compared to NiAl and similar to those observed for FeAl [9], even at low temperatures, where dislocation mobility is often limited for intermetallics. These low rate sensitivities suggest relatively high activation volumes for deformation and are an indication that the RuAl system is likely to possess good intrinsic deformability over a range of composition $[9,10]$.

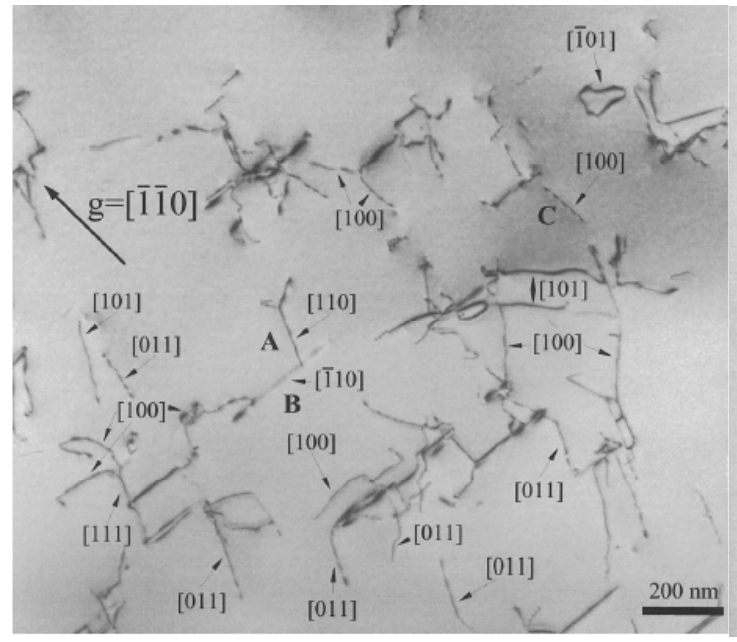

(a)

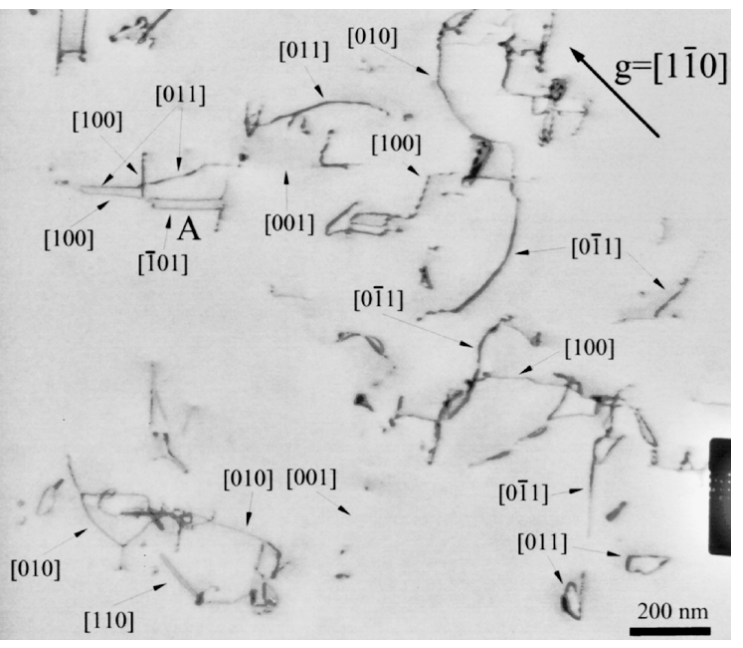

(b)

Fig. 2 - Dislocation substructures in RuAl deformed at (a) room temperature and (b) $77 \mathrm{~K}$.

\section{Ternary and Quaternary Alloys}

The objective of this portion of the investigation was to study the influence of solute additions on the low temperature deformation behavior. The approach was to select solute additions that were likely to substitute for the $\mathrm{Ru}$ and $\mathrm{Al}$, respectively, and perhaps influence fault energies and therefore deformation processes. Based on solute size 
factor and electronegativity considerations, Fig. 3, Pt and $\mathrm{Nb}$ are likely to substitute for the $\mathrm{Ru}$ and $\mathrm{Al}$, respectively. These two additions were selected for detailed investigation. Additionally, boron additions were investigated since they have been reported to improve the straining capacity of this material in compression [11]. The compositions of the materials studied are reported in Table 2.

Fig. 4 summarizes a series of bright field images of dislocations taken under different two-beam conditions for the RuAIPtB alloy. These experiments indicate that the majority of the dislocations in the field of view are [1 $\overline{1} 1]$ type dislocations (invisible for $g=\overline{1} 12$ ). The $<111>$ dislocations were observed in different grains examined over three separate foils, thus indicating that they were not isolated instances. The $<111>$ dislocation segments were long and exhibited significant curvature, indicating that they were essentially glissile and contributed to the overall deformation process. Curved segments of $<100>$ dislocations were also observed in some grains.

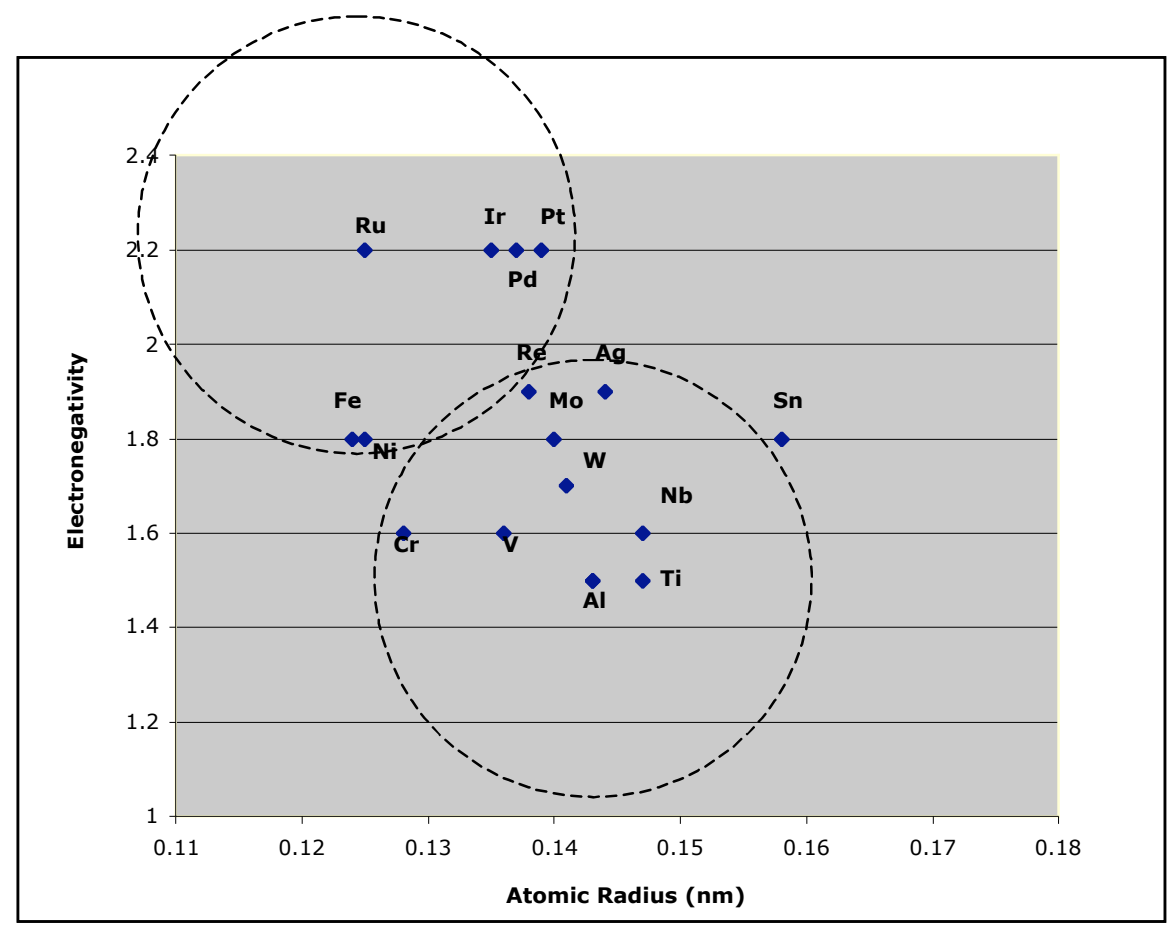

Fig. 3 - Atomic radii and electronegativities of selected elements relative to $\mathrm{Ru}$ and Al. Circles around $\mathrm{Ru}$ and $\mathrm{Al}$ indicate atomic radii within $15 \%$.

Table 2: Nominal composition (at\%) and grain sizes of the RuAl alloys.

\begin{tabular}{|c|c|c|c|c|c|}
\hline $\begin{array}{c}\text { Alloy } \\
\text { Designation }\end{array}$ & Al & B & $\begin{array}{c}\text { Other alloying } \\
\text { elements }\end{array}$ & $\mathrm{Ru}$ & $\begin{array}{c}\text { Grain size, } \\
\mathrm{m}\end{array}$ \\
\hline \hline RuAl & 50 & - & - & 50 & 200 \\
\hline RuAIB & 49.5 & 0.5 & - & 50 & 205 \\
\hline RuAIPtB & 49.5 & 0.5 & $2 \mathrm{Pt}$ & 48 & 120 \\
\hline RuAINb & $47 \mathrm{Al}$ & - & $3 \mathrm{Nb}$ & 50 & 210 \\
\hline
\end{tabular}


In the Nb-containing alloy, no such long, curved $<111>$ dislocations were observed. General features of the dislocation substructure for room and intermediate temperature deformation remained the same as the binary RuAl, being comprised of tangles and loosely defined cells of $\langle 100\rangle$ and $\langle 110\rangle$ dislocations. No discernible difference in dislocation substructure was observed after higher temperature deformation at $700^{\circ} \mathrm{C}$.
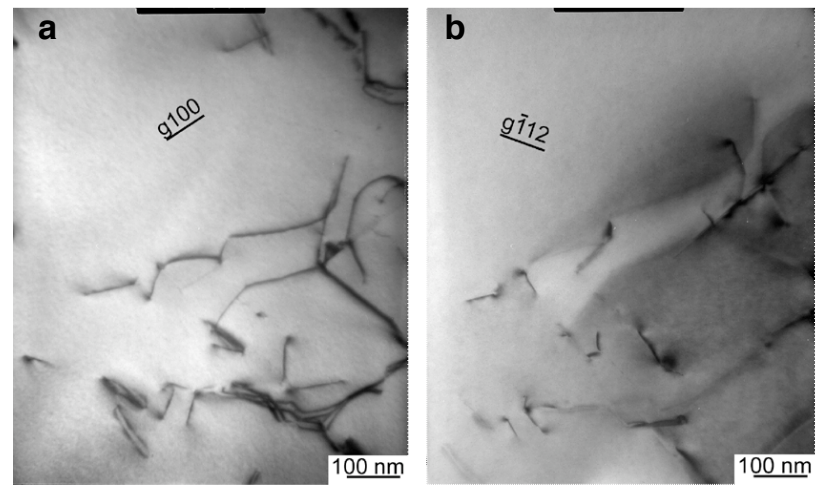

Fig. 4 - Dislocation substructure after room temperature deformation
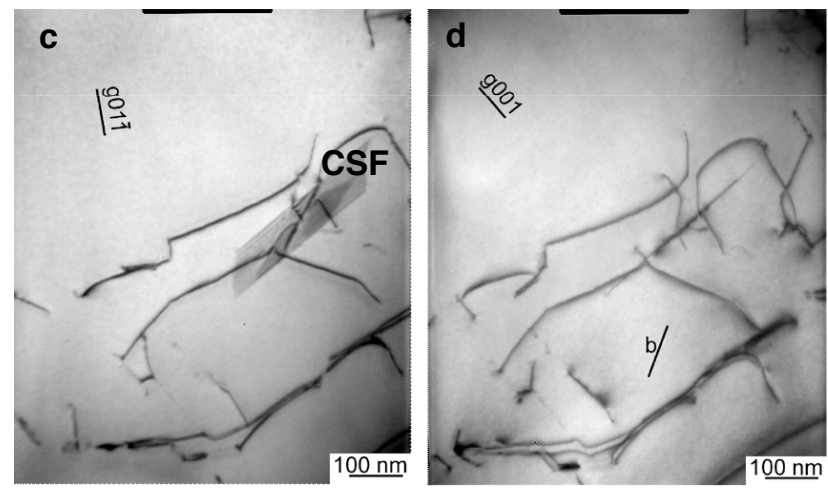
in the RuAIPtB alloy. Curved dislocations have $\left[\begin{array}{lll}1 & \overline{1} & 1\end{array}\right]$ Burgers vectors (invisible in micrograph b). Note the presence of a complex stacking fault (CSF) present prior to deformation.

The presence of $\langle 111>$ dislocations in the platinum-containing alloy is particularly interesting. As mentioned earlier, the APB energy on the $\{110\}$ plane appears to be the primary factor that influences the slip vector. First principles calculations $[12,13]$ have shown the APB energies on $\{110\}$ planes in NiAl, RuAl and FeAl to be 1000, 580 and $490 \mathrm{~mJ} / \mathrm{m}^{2}$, respectively. Since FeAl has a lower APB energy, the $<111>$ dislocation readily dissociates into two $<111>$ superpartials separated by a ribbon of APB [14]. In preliminary weak beam TEM studies on the Pt-containing material, shown in Fig. 5, the dissociation of the $<111>$ dislocation is apparent. No dissociation has yet been detected in the stoichiometric RuAl. For comparison it is interesting to note that when the $<111>$ is activated in single crystal $\mathrm{NiAl}$, it does not dissociate, but instead decomposes to $<100>$ and $<011>[15,16]$. Lin and coworkers [17] have shown a strong Ni p-Al d hybridization which influences the APB energy of dislocations in NiAl, while Ru d-Ru d bonding along the $<100>$ direction results in a lower degree of covalence in RuAl. The presence of the long, curved segments $<111>$ dislocations observed with the addition of 2at\% Pt suggests that the APB energy of RuAl may be lowered by the presence of platinum. We have also recently observed $<111>$ dislocation substructures in an alloy containing 4 at $\% \mathrm{Pt}$, suggesting that the presence of $<111>\mathrm{s}$ is not an isolated observation and not limited to a narrow range of composition. 
Finally, compression experiments were conducted in an intermediate temperature range from room temperature up to $900^{\circ} \mathrm{C}$ in binary and boron-containing materials. While no transitions in slip systems were observed as a function of temperature, a number of characteristics indicative of dynamic strain aging were observed, including serrated flow, flow stress plateau, maxima in the rate of work-hardening and reduced (and negative) strain-rate sensitivities. Static strain aging experiments were also conducted. The serrated flow was associated with the presence of interstitital solute that is mobile at $\mathrm{T} / \mathrm{T}_{\mathrm{m}} \approx 0.3$. A more detailed summary of results on the phenomenon of strain aging in RuAl alloys has already been published [18].

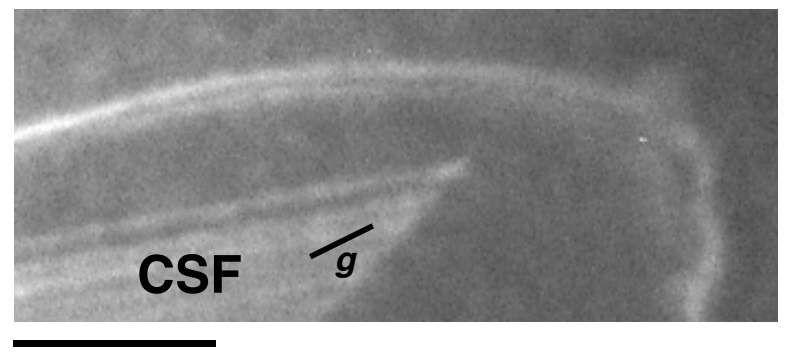

Fig. 5 - Weak beam TEM micrograph showing a dissociated $\left[\begin{array}{lll}1 & \overline{1} & 1\end{array}\right]$ dislocation for $g=\overline{1} 10$. Note the presence of a complex stacking fault (CSF), present prior to deformation due to boron additions.

\section{$50 \mathrm{~nm}$}

Viewing Figs. 4 and 5 again, a faulted structure is apparent (and marked as "CSF"). These faults were frequently observed in all boron-containing materials, in the as-cast and heat treated conditions. The character of these faults has been examined in detail by conventional two beam transmission electron microscopy experiments, Fig. 6. Bright field/dark field images reveal $\square$ fringe contrast. The faults were located on $\{001\}$ planes with displacement vectors of the type $\frac{1}{8}[40 \overline{1}]+\frac{1}{8}[00 \square]$, where $\square$ is a small number less than one. These faults were analyzed to be non-conservative substitutional complex faults arising from the substitution of aluminum by boron. The crystallography of the planar faults can be related to the crystallography of ternary borides of the type $\mathrm{Al}_{n-1} \mathrm{~B}_{2} \mathrm{X}_{n}$ (at\%), Fig. 7. Simulations of the fault contrast conducted by means of the crystal transfer matrix formalism [19] (with Professor Marc De Graef of Carnegie Mellon) were consistent with the experimental observations and mechanism of boron substitution to form single layer "precipitates" [20].

\section{Oxidation of RuAl Alloys}

Since intermetallics are generally interesting for their high temperature properties, preliminary cyclic oxidation experiments have been conducted (as an undergraduate project associated with this grant). A bottom loading cyclic oxidation furnace with fan cooling was utilized for these experiments. The thermal cycle consisted of a 20 minute heatup time to maximum temperature, a 55 minute hold at peak temperature and a ten minute fan-assisted cooling cycle to room temperature. Experiments were conducted 


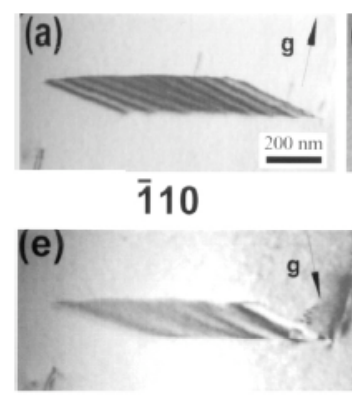

$1 \overline{2} 1$

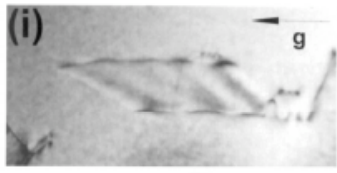

$21 \overline{1}$

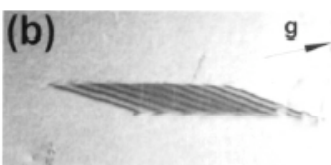

$01 \overline{1}$

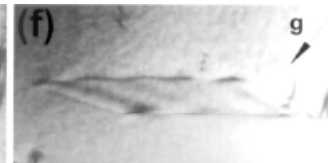

$2 \overline{1} \overline{1}$

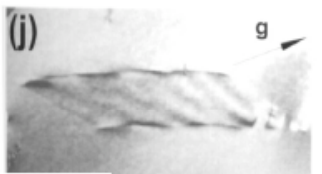

200

(m)

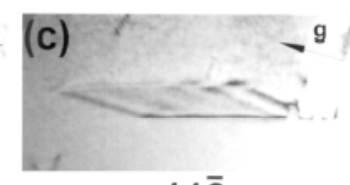

$11 \overline{2}$

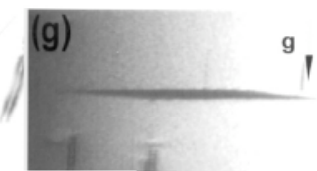

$1 \overline{10}$

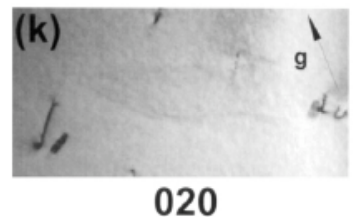

(n)

010

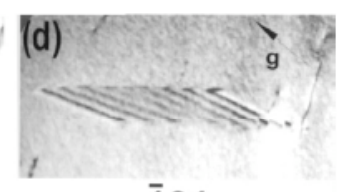

$\overline{101}$

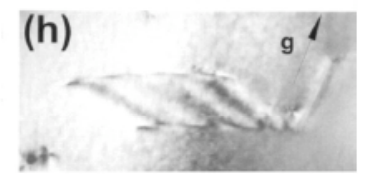

$\overline{2} 1 \overline{1}$

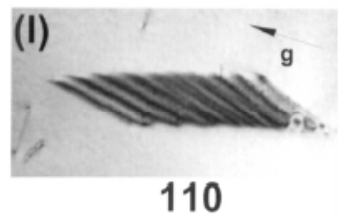

100

Fig. 6 -Bright field images of a planar fault in $\mathrm{RuAl}+0.5 \% \mathrm{~B}$ for 14 different diffracting vectors.

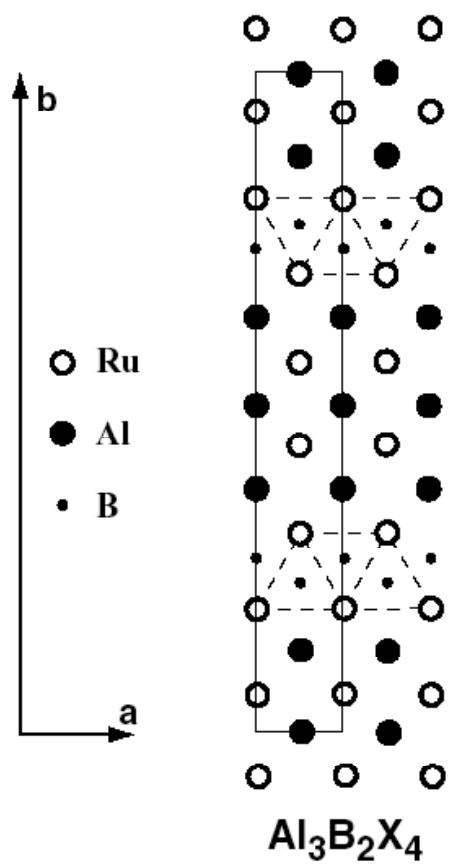

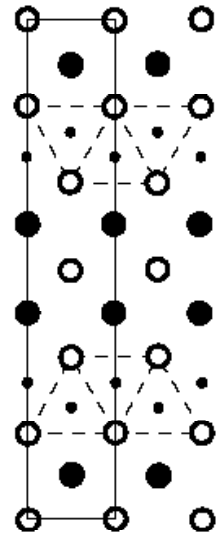

$\mathrm{Al}_{2} \mathrm{~B}_{2} \mathrm{X}_{3}$

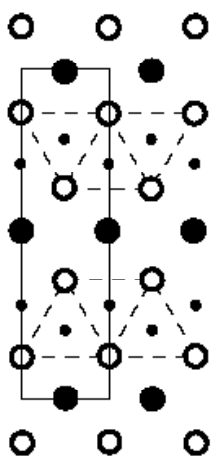

$\mathrm{AlB}_{2} \mathrm{X}_{2}$

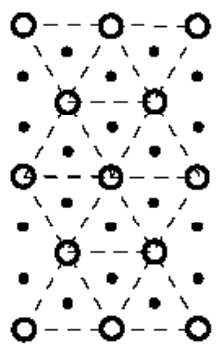

$B_{2} X$

Fig. 7 - Sequence of phases of the type $\mathrm{Al}_{n-1} \mathrm{~B}_{2} \mathrm{X}_{n}$ for $n=4,3,2$ and 1 . The C-centered orthorhombic unit cell (space group $\mathrm{Cmmm}$ ) with $b$ along the long axis is outlined for $n>$ 1. The final diboride structure $B_{2} X$ has a hexagonal $C 32$ structure with space group $\mathrm{P} 6 / \mathrm{mmm}$. 
with peak temperatures in the range of $1000^{\circ} \mathrm{C}-1300^{\circ} \mathrm{C}$.Fig. 8 shows selected results for experiments conducted at $1000^{\circ} \mathrm{C}$, which were qualitatively similar to those conducted at other temperatures.

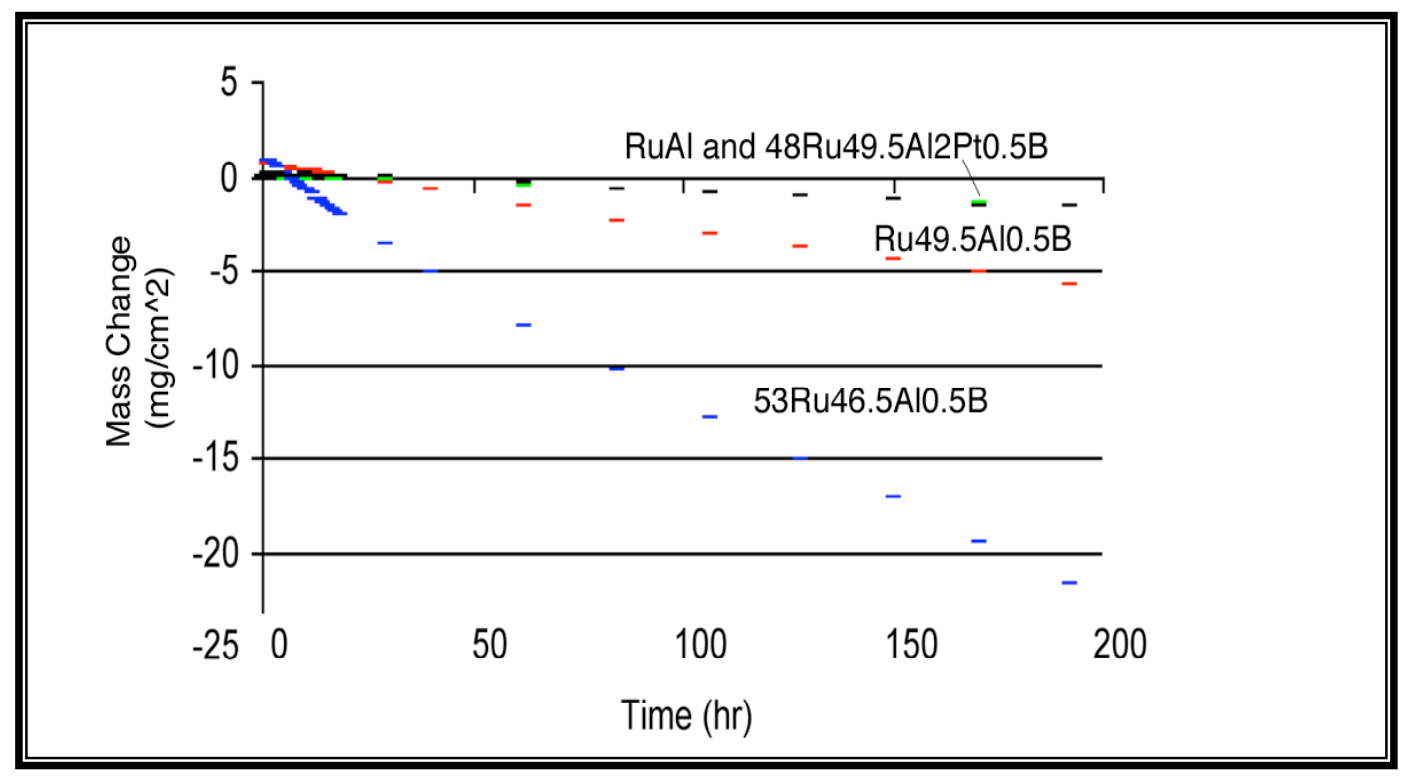

Fig. 8 - Cyclic oxidation behavior of RuAl alloys for a cycle with a peak temperature of $1000^{\circ} \mathrm{C}$.

In all cases alloys with excess $\mathrm{Ru}$ in the form of the hcp $\square$ phase (which is $>95 \% \mathrm{Ru}$ ) oxidized most rapidly, with near-linear weight losses with time. Elemental $\mathrm{Ru}$ is known to have poor oxidation properties at temperatures of $1000^{\circ} \mathrm{C}$ and higher due to vaporization of ruthenium oxides [21, 22]. Thus alloys containing significant fractions of the $\square$ phase oxidized rapidly along grain boundaries where this phase was initially located during solidification. Stoichiometric RuAl (without the $\square$ phase) gained weight in the early stages of oxidation, but then also suffered weight loss with time. Alloys with Pt additions generally displayed the best oxidation resistance over the temperature range investigated. The weight loss behavior can be understood in view of the morphology of the oxidized scale, Fig. 9. It consists of an outer porous layer of primarily $\square$-alumina. Beneath this are alternating layers of alumina and $\square R u$ (the bright phase). Viewing the oxide layers, it appears that the mechanism for forming this layered structure consists of initial formation of alumina, which results in rejection of $\mathrm{Ru}$ beneath the alumina layer. The Ru layer forms because there are no intermediate phases between RuAl and $[\mathrm{Ru}$ (see the phase diagram in Fig. 10). We hypothesize that cracking or spallation of the alumina layer, once it exceeds a critical thickness, results in rapid oxygen diffusion into the Ru layer, which then oxidizes and vaporizes. For this reason, the outer layers of the oxide are somewhat porous and devoid of $\mathrm{Ru}$, while the inner alternating layers still contain Ru. WDS microprobe analyses confirm that Pt partitions to the Ru layers, apparently increasing resistance to cracking. Additional cyclic oxidation experiments on a Ru-15Pt alloy (of the same composition of the Ru-rich layer formed on (Ru,Pt)Al alloys), demonstrated no influence of $\mathrm{Pt}$ on vaporization kinetics. Further studies are 
clearly required to quantitatively relate weight loss kinetics to scale formation, vaporization and spallation.

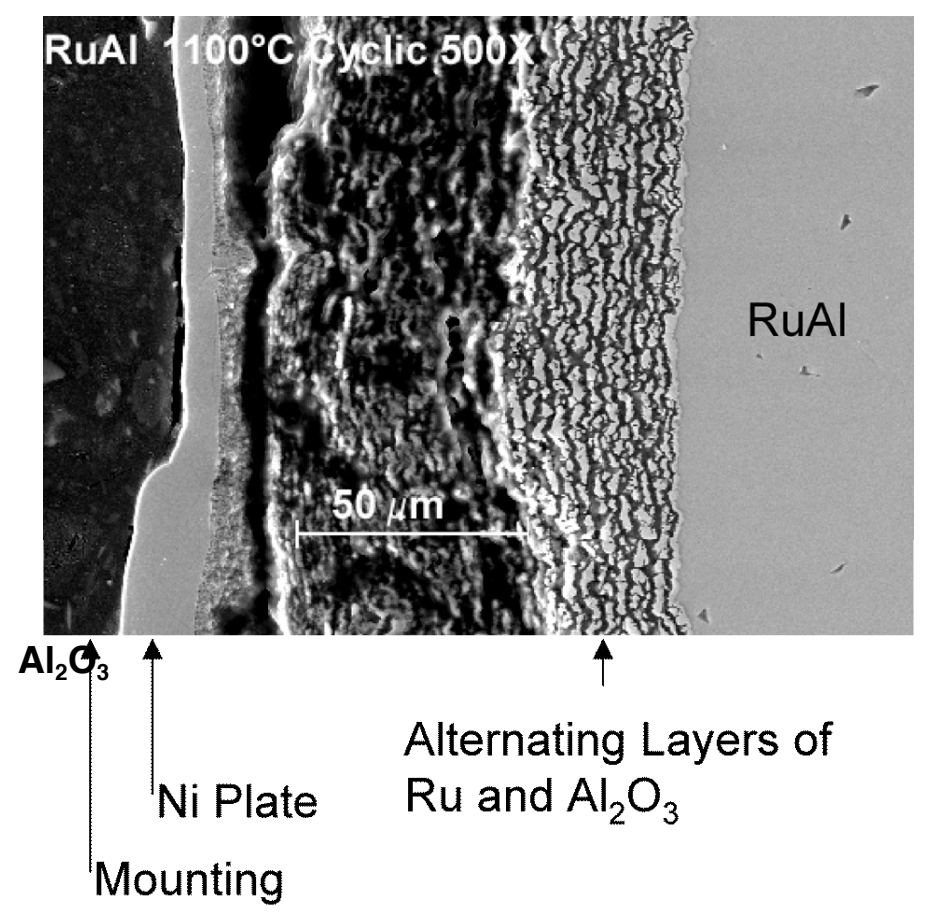

Fig. 9 - Structure of oxide layers on RuAl following cyclic oxidation at $\mathrm{T}_{\max }=1100^{\circ} \mathrm{C}$.

\section{Preliminary Creep Experiments}

Since intermetallics are ultimately of interest for use at high temperatures, their high temperature creep properties are important. This aspect of their behavior has not yet been investigated for RuAl. We have recently conducted several creep experiments to obtain an estimate of the creep rate (in compression) of RuAl, compared to NiAl. Experiments were conducted in a specially designed vacuum creep apparatus with the extensometry contained inside the vacuum furnace, shielded from the hot zone. For reference purposes a [001] NiAl single crystal was crept at $20 \mathrm{MPa}$ to obtain a creep rate $10^{-8} / \mathrm{s}$, consistent with prior observations for $\mathrm{NiAl}[9,10,45]$. Following this, a polycrystal RuAl sample of the same dimensions was tested in the same apparatus.

No creep was observed until a stress of $500 \mathrm{MPa}$ was reached. The procedure was repeated several times alternating between $\mathrm{NiAl}$ and RuAl samples, with very similar results. A temperature of $1050^{\circ} \mathrm{C}$ represents $T / T_{m}=0.70$ for $\mathrm{NiAl}$ and $T / T_{m}=0.59$ for RuAl. Assuming a typical creep stress exponent $(n=5)$ and activation energy for creep for $\operatorname{NiAl}(Q=314 \mathrm{~kJ} / \mathrm{mol})$ : 


$$
\square=A \square^{n} \exp \cap \frac{Q}{R T}=
$$

it can be estimated that the RuAl should sustain a stress of $70 \mathrm{MPa}$ to compensate for being held at a correspondingly lower homologous temperature. The high temperature strength measured is clearly much beyond this, even for a polycrystalline sample. It is unlikely that this differences in activation energies for diffusion / creep could account for this. Instead qualitative differences in the dislocation glide and climb processes must be responsible. Investigation of dislocation substructures and deformation mechanisms across the NiAl-RuAl ternary B2 field would certainly be of interest in future research programs.

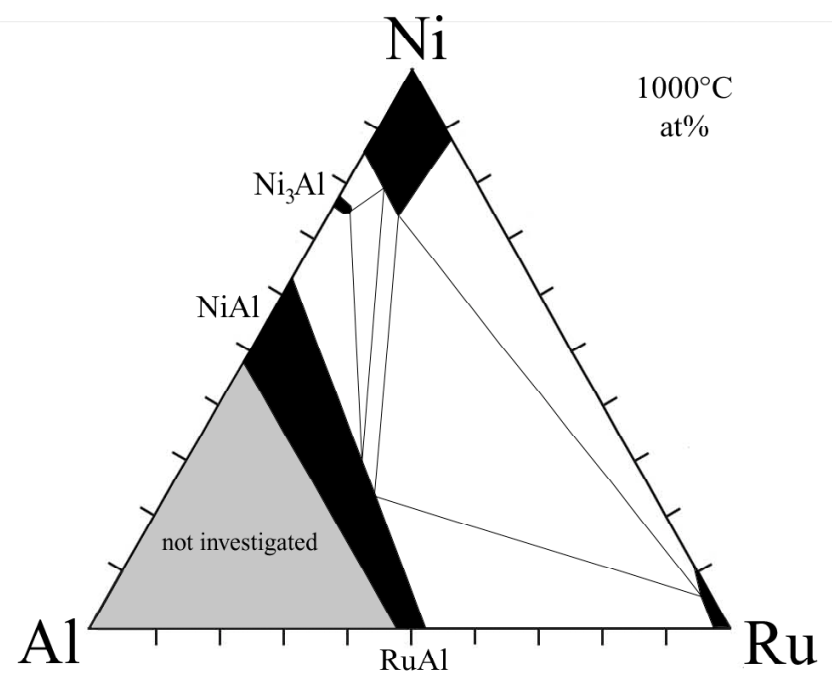

Fig. 10 - The ternary Ni-Al-Ru phase diagram experimentally assessed by Tryon and co-workers at the University of Michigan. 


\section{Personnel Supported}

This program has supported one Ph.D. student (Dr. David Lu, who received his degree in 2000), one postdoctoral researcher, (Dr. Tapash Nandy, now at DMRL, Hyderabad, India), one undergraduate researcher (Mr. David Stobbe, who is now a graduate student at Georgia Tech). The grant also supported a Ph.D. student, Ms. Fang Cao, for the first half of a Ph.D thesis.

\section{Publications and Presentations}

Mechanical Behavior of Ternary and Quaternary RuAl Alloys, T. K. Nandy, Q. Feng, D. Banerjee, M. F. X. Gigliotti, T. M. Pollock, MRS Symp. Proc., Defect Properties and Related Phenomena in Intermetallic Alloys (USA), pp. 89-94, (2003).

Deformation of a Platinum-containing RuAl Intermetallic by $<111>$ Dislocations T.K. Nandy, Q. Feng and T.M. Pollock, Scripta Mater. 48, 1087, (2003).

Transmission Electron Microscopy Study of Complex Planar Faults in RuAl-0.5\%B, D.-C. Lu, M. De Graef and T.M. Pollock, Phil. Mag. A84, 22, 2317, (2004).

Elevated Temperature Deformation and Dynamic Strain Aging in Polycrystalline RuAl alloys, T. K. Nandy, Q. Feng, T. M. Pollock, Intermetallics (UK), vol. 11, no. 10, pp. 1029-1038, (2003).

A Comparative Analysis of Low Temperature Deformation in B2 Aluminides, T.M. Pollock, D.C. Lu, X. Shi and K. Eow, Materials Science and Engineering A, vol. 317, no. 1-2, pp. 241-248, (2001).

Complex Planar Faults in Ru-Al-0.5at\% B and Their Relation to Transition Metal Borides, D.C. Lu, M. De Graef and T.M. Pollock, Minerals, Metals and Materials Society/AIME, Structural Intermetallics 2001 (USA), pp. 541-549, (2001).

The Role of Platinum Additions in Deformation of RuAl Alloys, T.K. Nandy, D. Banerjee and T.M. Pollock, in preparation for submission to Phil Mag A (2005).

Oxidation of Ruthenium Aluminide-Based Alloys: The Role of Microstructure and Platinum Additions, F. Cao, D. Stobbe, T.K. Nandy and T.M. Pollock, J. Intermetallics, submitted, (2005).

Mechanical Behavior and Dislocation Substructure in RuAl Alloys

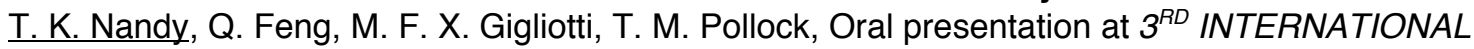
SYMPOSIUM ON STRUCTURAL INTERMETALLICS, April 28-May 2, 2002 · Jackson Hole, Wyoming.

Dynamic Strain Aging in Polycrystalline RuAl Alloys T. K. Nandy, Q. Feng, T. M. Pollock, Oral Presentation at TMS FALL MEETING 2002 · Columbus, Ohio, October 6-10, 2002. 
Mechanical Behavior of Ternary and Quaternary RuAl Alloys

T. K. Nandy, Q. Feng, M. F. X. Gigliotti, T. M. Pollock, Oral Presentation at TMS FALL MEETING $2002 \cdot$ Columbus, Ohio, October 6-10, 2002.

Mechanical Behavior of Ternary and Quaternary RuAl Alloys

T. K. Nandy, Q. Feng, D. Banerjee, M. F. X. Gigliotti, T. M. Pollock

Oral Presentation in 2002 MRS Fall Meeting, December 2-6, 2002, Boston.

High Temperature Oxidation of RuAl and RuAl Alloys

D. Stobbe, T. K. Nandy, Q. Feng and T.M. Pollock, Poster Presentation atTMS Annual Meeting,

San Diego, CA, March 4, 2003. (Best Poster Award).

Intermetallics as Structural Materials

T.M. Pollock (invited), 50th Anniversary of the University of Science and Technology Beijing,

International Workshop on Advanced Metallic Materials, April 21, 2002.

RuAl and Bond Coats for Thermal Barrier Coatings

T.M Pollock (invited), Workshop on Science and Technology of Thermal Barrier Coatings,

September 9-11 2001, Ocean City, New Jersey.

\section{References}

1. I.M. Wolff, Metall. Mater. Trans. 27A, 3688, (1996).

2. R. L. Fleischer and R. J. Zabala, Metall. Trans., 21A, 2709, (1990).

3. I.M. Wolff, JOM, 1, 34, (1997).

4. R.L. Fleischer and D.W. McKee, Metall. Trans. 24A, 759, (1993).

5. E.G. Smith and C.I. Lang, Scripta Mater. 33, 1225, (1995).

6. B. Tryon, T.M. Pollock, M.F.X. Gigliotti and K. Hemker, Scripta Mater., 50, 845 - 848, (2004).

7. D. Lu and T.M. Pollock, Acta Mater., 47, 1035, (1999).

8. K. Eow, D. Lu and T.M. Pollock, Scripta Mater. 38, 1065, (1998).

9. T.M. Pollock, D.C. Lu, X. Shi and K. Eow, Mater. Sci. Eng. A317, $241-248$, (2001).

10. U.F. Kocks, A.S. Argon and M.F. Ashby, Prog. Mat. Sci., 19 (1975).

11. R. L. Fleischer, R.D. Field and C.L. Briant, Metall. Trans., 22A, 403, (1991).

12. A.J. Freeman, J.-H. Xu, T. Hong and W. Lin, Ordered Intermetallics: Physical Metallurgy and Mechanical Behavior, Kluwer Acad., FRG, Dordrecht, 1991.

13. A.J. Freeman, T. Hong, W. Lin, J-H. Xu and L.A. Johnson, High Temperature Ordered Intermetallics IV, D.P. Pope, J. O. Stiegler, editors., Mater Res Symp Proc, vol. 213., 3, (1991).

14. D.G. Morris, J.C. Joye and M. Leboeuf, Phil. Mag 69A, 961, (1994).

15. J.T. Kim and R. Gibala, High Temperature Ordered Intermetallics IV, D.P. Pope, J. O. Stiegler, editors., Mater Res Symp Proc, vol. 213, 261, (1991).

16. R. Srinivasan, M.F.Savage, M.S. Daw, R.D. Noebe, A. Garg and M.J. Mills, Structural Intermetallics, (eds: Nathal MV, Darolia R, Liu CT, Martin PL, Miracle DB, Wagner R and Yamaguchi M), The Minerals, Metals and Materials Society, 665, (1997).

17. W. Lin, J. Xu and A.J. Freeman, J. Mater. Res. 7, 592, (1992).

18. T. K. Nandy, Q. Feng, T. M. Pollock, Intermetallics, 11 1029, (2003).

19. A. Tholen, Phil. Mag., 22, 175, (1970).

20. D.-C. Lu, M. De Graef and T.M. Pollock, Phil. Mag. A, 84, 22, 2317, (2004).

21. G. Bayer and H.G. Wiedemann, Thermochimica Acta 11, 79, (1975).

22. C.A. Krierandn R.I. Jaffe, J. Less Common Metals 5, 411, (1963). 